CASE REPORT

\title{
Sunitinib Induced Cytopenia in Metastatic RCC
}

\section{Aykut Bahçeci ${ }^{1 *}$, M Metin Şeker ${ }^{2}$, Turgut Kaçan ${ }^{2}$, Nalan Akgül Babacan², Birsen Yücel ${ }^{3}$ and M Asım Gedikli}

${ }^{1}$ Department of Medical Oncology, Gaziantep Dr. Ersin Arslan Education and Research Hospital, Turkey

${ }^{2}$ Department of Medical Oncology, Cumhriyet University School of Medicine, Turkey

${ }^{3}$ Department of Radiation Oncology, Cumhriyet University School of Medicine, Turkey

${ }^{4}$ Department of Internal Medicine, Cumhriyet University School of Medicine, Turkey

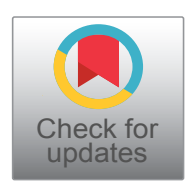

*Corresponding author: Aykut Bahceci, MD., Department of Medical Oncology, Gaziantep Dr. Ersin Arslan Education and Research Hospital, 27010, Gaziantep, Turkey, Tel: +90-342-221-07-00, E-mail: aykutbahceci@gmail.com

\section{Keywords \\ Sunitinib, Cytopenia, RCC, Treatment}

\section{Introduction}

Most malignant kidney tumors are renal tubular epithelium derived adenocarcinomas and referred to as renal cell carcinoma (RCC). Kidney cancer accounts for 3-4\% of adult cancers and one third of the overall cases of RCC are diagnosed at the advanced stages of the disease [1-3]. RCC is a chemo-radioresistant cancer. Therefore, immunomodulatory agents and tyrosine kinase inhibitors (TKI) are commonly used in the treatment of mRCC.

Sunitinib is an oral TKI with activity against vascular endothelial growth factor receptor (VEGFR) as well as with an inhibiting activity against many other tyrosine kinase receptors, including c-KIT, FLT3 platelet derived growth factor receptors (PDGFR) [4].

Although effective in the treatment of RCC, sunitinib may cause fatigue, nausea, diarrhea, stomatitis and myelosuppression. Apart from myelosuppression, side effects are usually tolerable. However myelosuppression may be severe enough to require dose reductions or discontinuation of the therapy [5]. Suggested dose levels of Sunitinib are $50 \mathrm{mg}, 37.5 \mathrm{mg}$ and $25 \mathrm{mg}$. Doses reduced for toxicity should not be reescalated.

We aimed at presenting four cases of Sunitinib induced myelosuppression, in which we continued the therapy with dose modifications and recovery from myelosuppression was observed during the follow up period.

\section{Case Presentation}

\section{Case 1}

A 72-year-old male patient. RCC metastatic to the lungs at the time of diagnosis. The patient developed Grade 1 leukopenia, anemia and thrombocytopenia in the third month of the therapy with Sunitinib. The sunitinib dose was reduced to $37.5 \mathrm{mg}$. In the sixth month of therapy, in spite of a Grade 2 leukopenia and neutropenia, a complete response was obtained in the lung lesions. Any further reduction in the Sunitinib dose was not carried out due to the significant clinical response. The patient is still progression free in the $37^{\text {th }}$ month of the therapy with sunitinib $37.5 \mathrm{mg}$.

\section{Case 2}

A 66-year-old female patient. Sunitib was initiated due to the recurrence of the abdominal tumor, 4 years after the diagnosis of RCC. She developed Grade 2 thrombocytopenia in the fourth month of the therapy with Sunitinib. Sunitinib treatment was continued at dose reduced to $37.5 \mathrm{mg}$. The resolution of cytopenia occurred 2 months later. The patient was progression free during the next 7 months. The overall duration of the therapy with Sunitinib was 11 months. The therapy was switched from sunitinib to everolimus due to the disease progression of abdominal masses.

\section{Case 3}

A 61-year-old male patient. Lung metastasis was detected 7 years after the diagnosis of RCC and sunitinib

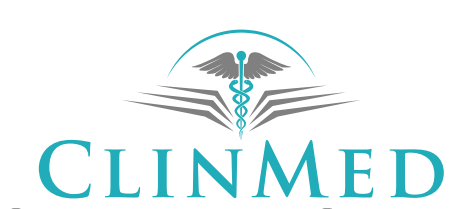

INTERNATIONAL LIBRARY

Citation: Bahçeci A, Şeker MM, Kaçan T, Babacan NA, Yücel B, et al. (2018) Sunitinib Induced Cytopenia in Metastatic RCC. Clin Med Rev Case Rep 5:208. doi.org/10.23937/2378-3656/1410208

Accepted: March 28, 2018: Published: March 30, 2018

Copyright: (c) 2018 Bahçeci A, et al. This is an open-access article distributed under the terms of the Creative Commons Attribution License, which permits unrestricted use, distribution, and reproduction in any medium, provided the original author and source are credited. 
was started. Although he developed Grade 2 leukopenia and thrombocytopenia and Grade 2 neutropenia in the $3^{\text {rd }}$ month of the therapy with sunitinib, the medicine was continued at dose of $50 \mathrm{mg}$ during the next 16 months. The patient developed Grade 3 anemia, Grade 2 leukopenia and neutropenia and Grade 1 thrombocytopenia in the $19^{\text {th }}$ months of the treatment. Therefore the dose was reduced to $37.5 \mathrm{mg}$. The patient has received sunitinib at dose of $37.5 \mathrm{mg}$ during the last 6 months and no progression was detected during this period of follow up.

\section{Case 4}

A 42-year-old male patient. Cranial metastasis was detected 11 years after the diagnosis of RCC. He developed Grade 3 leukopenia, neutropenia, anemia and Grade 4 thrombocytopenia leading to the discontinuation of the therapy with sunitinib, 18 months after the initiation of therapy. Later on, sunitinib was resumed at dose of 37.5 $\mathrm{mg}$. However, due to the recurrence of Grade 2 leukopenia and neutropenia, sunitinib was continued with a dosing schedule of two weeks off and two weeks on. After the resolution of cytopenia at this level of dose, dosing schedule was readjusted as 4 weeks on and 2 weeks off and the patient was progression-free during the next 9 months then the therapy was switched from sunitinib to everolimus as a consequence of cranial metastasis.

\section{Discussion}

TKls are used in the management of cancer, in an increasing frequency [6]. The high efficacy and easy administration of TKls allow a longer duration of treatment in comparison to the standard chemotherapeutic regimens, which in turn highlights the importance of the side effects.

One of the most serious side effects of TKIs is myelosuppression. In vitro studies revealed that the inhibitory activity of sunitib against c-KIT and FLT3 kinases was higher than the other TKIs [7]. However, the exact mechanism of myelosuppression is not fully understood. In addition to sunitinib, myelosuppression is also associated with the use of sorafenib or pazopanib $[8,9]$. The results of a meta-analysis performed by Funokoshi, et al. have supported this association. This meta-analysis included 8526 patients from 60 studies. The incidence of neutropenia or thrombocytopenia were found to be higher with sunitinib in comparison to sorafenib and pazopanib. The same studies also revealed the associations between sunitinib and all grades (Grade 1,2,3,4) and high grades (Grade 3,4 ) neutropenia and thrombocytopenia and all grades anemia (Grade 1,2,3,4) [10].

In a study comparing INF to sunitinib, sunitinib was found to be associated with leukopenia, neutropenia, anemia and thrombocytopenia in all grades, in more than the half of the patients. Transient Grade 3 or Grade 4 neutropenia and thrombocytopenia may be observed in patients who receive sunitinib more than 6 months [11].

Gradual dose reductions of $12.5 \mathrm{mg}$ are recommended in case of intolerance and hematological toxicity and discontinuation of the therapy is recommended in case of the emergence of Grade 3 or 4 toxicity [5]. However, due to the high level of efficacy of sunitinib in RCC, many centers continue sunitinib therapy with dose modifications. We continued the therapy with sunitinib with dose modifications and observed the resolution of the toxicity during the follow up of the patients and by this means, these patients achieved a long term progression free survival.

\section{Conclusion}

Sunitinib is a highly efficient agent in the treatment of metastatic RCC. In case of sunitinib induced toxicity, the management of toxicity should be considered first. This may serve to preserve other treatment options as well as to increase the length of progression free survival.

\section{References}

1. Jemal A, Siegel R, Ward E, Hao Y, Xu J, et al. (2008) Cancer statistics, 2008. CA Cancer J Clin 58: 71-96.

2. Lam JS, Leppert JT, Belldegrun AS, Figlin RA (2005) Novel approaches in the therapy of metastatic renal cell carcinoma. World J Urol 23: 202-212.

3. Motzer RJ, Bander NH, Nanus DM (1996) Renal-cell carcinoma. N Engl J Med 335: 865-875.

4. Mendel DB, Laird AD, Xin X, Louie SG, Christensen JG, et al. (2003) In vivo antitumor activity of SU11248, a novel tyrosine kinase inhibitor targeting vascular endothelial growth factor and platelet-derived growth factor receptors: determination of a pharmacokinetic/pharmacodynamic relationship. Clin Cancer Res 9: 327-337.

5. Kollmannsberger C, Soulieres D, Wong R, Scalera A, Gaspo $R$, et al. (2007) Sunitinib therapy for metastatic renal cell carcinoma: recommendations for management of side effects. Can Urol Assoc J 1: S41-S54.

6. Rini BI, Choueiri TK, Elson P, Khasawneh MK, Cotta C, et al. (2008) Sunitinib-induced macrocytosis in patients with metastatic renal cell carcinoma. Cancer 113: 1309-1314.

7. Kumar R, Crouthamel MC, Rominger DH, Gontarek RR, Tummino PJ, et al. (2009) Myelosuppression and kinase selectivity of multikinase angiogenesis inhibitors. $\mathrm{Br} \mathrm{J}$ Cancer 101: 1717-1723.

8. Schutz FA, Je Y, Choueiri TK (2011) Hematologic toxicities in cancer patients treated with the multi-tyrosine kinase sorafenib: a meta-analysis of clinical trials. Crit Rev Oncol Hematol 80: 291-300.

9. Sternberg CN, Davis ID, Mardiak J, Szczylik C, Lee E, et al. (2010) Pazopanib in locally advanced or metastatic renal cell carcinoma: results of a randomized phase III trial. J Clin Oncol 28: 1061-1068.

10. Funakoshi T, Latif A, Galsky MD (2013) Risk of hematologic toxicities in cancer patients treated with sunitinib: a systematic review and meta-analysis. Cancer Treat Rev 39: 818-830.

11. Motzer RJ, Hutson TE, Tomczak P, Michaelson MD, Bukowski RM, et al. (2007) Sunitinib versus interferon alfa in metastatic renal-cell carcinoma. N Engl J Med 356: 115-124. 